\title{
Experimentos Audiovisuais entre Ramagens Otonianas: uma leitura ecossistêmica comunicacional sobre a representação da Amazônia na arte de Otoni Mesquita
}

Experimentos audiovisuales en los aspectos Otonianos: un ecosistema comunicacional en la representación de la Amazônia en el arte de Otoni Mesquita

\section{Creative ramifications: An ecosystem reading on the Amazon by Art Otoni Mesquita}

Ítala Clay de Oliveira Freitas'

Rafael de Figueiredo Lopes"

Palavras chave:

Resumo:

Ecossistemas

comunicacionais

Arte

Audiovisual

Amazônia

Otoni Mesquita

O artigo propõe uma leitura ecossistêmica comunicacional sobre aspectos da obra do artista visual amazonense Otoni Mesquita, com destaque para seus vídeos experimentais. A perspectiva metodológica segue preceitos do pensamento complexo e sistêmico. A investigação sugere que a semiose do transcurso comunicativo, que emerge da criatividade e postura ética do artista, impulsiona inúmeras percepções e desdobramentos sobre processos de criação na arte contemporânea e reflexões acerca de transformações socioculturais e ambientais na Amazônia. 


\section{Resumen:}

El artículo propone una lectura sobre la base de lo ecosistema comunicacional sobre aspectos de la obra del artista amazonense Otoni Mesquita, destacando sus videos experimentales. La perspectiva metodológica sigue los preceptos del pensamiento complejo y sistémico. La investigación sugiere que la semiosis por supuesto comunicativo, que surge de lacreatividad y la postura ética del artista, conduce a innumerables percepciones y desarrollos sobre losprocesos de creación en arte contemporáneo y las reflexiones sobre las transformaciones socio-culturales y ambientales enl a Amazonía.
Palabras clave:

Ecosistemas

Comunicacionales

Arte

Sector audiovisual

Amazônia

Otoni Mesquita

\section{Keywords:}

Communicational ecosystems

\section{Art}

Video

Amazon

Otoni Mesquita

\section{Abstract:}

This paper proposes an ecosystem reading on aspects of the visual artist's collection Otoni Mesquita, highlighting experimental videos. The methodological approach follows the precepts of the Paradigm of Complexity. Research suggests that semiosis communicative course, emerging creativity and ethical artist provides numerous insights mainly on developments on creative processes in contemporary art and reflections on social, cultural and environmental in the Amazon. 


\section{Experimentos Audiovisuais entre Ramagens Otonianas: uma leitura ecossistêmica comunicacional sobre a representação da Amazônia na arte de Otoni Mesquita}

\section{Introdução}

O artigo exploraaspectos do contexto criativo-comunicacional que envolve a vida e a obra do artista visual amazonense Otoni Mesquita, destacando uma de suas facetas menos conhecidas: a produção audiovisual. Buscamos uma compreensão ecossistêmica, ao refletirmos sobre desdobramentos do universo imagéticoOtoniano, partindo contextualmente da principal temática engendrada no conjunto de seu trabalho, intitulada Ciclos do Eldorado, na qual delineiauma visão particular sobre a Amazônia.

Otoni Mesquita interage com um repertório multi-expressivo de linguagens artísticas, tais como pintura, escultura, gravura, instalação, ensaio literário, performance, teatro e audiovisual. Essa dinâmica rede de manifestações artísticas e comunicativas, que se configura como um ecossistema comunicacional, denominamos ramagens otonianas. Consequentemente, por entre as ramagens,florescem o que chamamos de seus experimentos audiovisuais, os quais interpretamos como $((($ ecos $)))$ ou ideias-imagens-reverberantesem que ressoam inúmeros discursos e experimentações estéticas.

Nossa investigação é orientada por novos paradigmas da ciência, estabelecidos pelo pensamento complexo e sistêmico, propondo a construção de um conhecimento relacional no intuito de evitar balizamentos reducionistas. Segundo Morin (2002) a construção do conhecimento é um processo "auto-eco-organizador", sempre em transformação, devido às dimensões sensíveis e cognitivas, que organizam e desorganizam a consciência sobre o que nos rodeia. Um circuito em movimento ativando inter-relações entre os sistemas da vida. Segundo o autor, o pensamento complexo é ecológico porque não separa a dimensão humana (biológica, psíquica, espiritual) da relação com seus ambientes (social, cultural, econômi$\mathrm{co}$, político, natural etc.). Portanto, o sentido dialógico do "princípio hologramático", defendido por Morin (2002), é uma associação de complementaridades, concorrências e antagonismos, em constantes divergências e conciliações provisórias.

Sendo assim, nos guiamos pela perspectiva teórico-metodológica,inter e transdisciplinar, dos Ecossistemas Comunicacionais, proposta pelo Programa de Pós-Graduação em Ciências da Comunicação da Universidade Federal do Amazonas, que está em consonância comprincípiose pensadores que acreditam em uma reforma de ordem epistemológica e prática do fazer científico, compreendendo que há "inter-relações e interdependências entre os fenômenos físicos, biológicos, psicológicos, sociais e culturais" (MONTEIRO; ABBUD; PEREIRA, 2012).

Essa visão transcende as atuais fronteiras disciplinares e conceituais [...]. Não existe no presente momento, uma estrutura bem estabelecida, conceitual ou institucional, que acomode a formulação do novo paradigma, mas as linhas mestras de tal estrutura já estão sendo formuladas por muitos indivíduos, comunidades e organizações que estão desenvolvendo novas formas de pensamentos e que se estabelecem com novos princípios (CAPRA, 2006, p. 259).

Para Capra (2002) o maior desafio é mudar a maneira de pensar a ciência, descortinando uma nova visão da 
realidade. Segundo o autor, é necessário ultrapassar as noções mecanicistas e reducionistas, que ainda guiam muitas teorias ancoradas no pensamento cartesiano-newtoniano. De acordo com Capra (2002) o pensamento ecológico (que para ele é sinônimo de sistêmico e, portanto, para nós, ecossistêmico) não percebe os elementos de forma isolada, nem os segmenta ou padroniza. Para compreendê-los faz relações por interdependências contextuais com variados níveis de complexidade e incertezas. É uma perspectiva intrinsicamente dinâmica, capaz de aliar o conhecimento racional com a intuição da natureza não- linear do ambiente, entrelaçando seus elementos, em movimentos cíclicos, flutuantes, ondulatórios, vibrantes e oscilatórios (CAPRA, 2002).

Pelo fato de nos concentrarmos em torno da compreensão da obra de um artista que busca inspiração nas multiplicidades da Amazônia e a representa por diferentes ângulos e suportes, procuramos inter-relacionar estéticas e linguagens artísticas com aspectos históricos, humanos, ambientais, socioculturais e tecnológicos, a fim de apresentar uma possibilidade de leitura sobre o fenômeno.

Desse modo, o conceito de representação é fundamental para a nossa reflexão, salientando que em função de nossa linha de pesquisa, optamos por caracterizá-lo pelo viés da semiótica. Conforme Santaella (2003) o ser humano só concebe o mundo porque de alguma forma o representa e, consequentemente, só interpreta tal representação por meio de outra representação, um signo. Esse processo pode ser gerado a partir de imagens mentais ou palpáveis, pelo gestual, por ações, sons, palavras, sentimentos etc.

No percurso signo-significação-representação, segundo Santaella e Nöth (1999), tudo o que se apresenta às percepções e ao intelecto, de forma material ou em pensamento, pode ser signo. A ação do signo, ou seja, a semiose, proporciona uma significação que vai gerar uma representação. Isto é, o signo representa a ideia de uma coisa e não a coisa em si.

Essa concepção pode ser melhor compreendida pela relação triádica da semiótica peirceana, que se constitui na triangulação signo-objeto-interpretante, de acordo com Santaella e Nöth (1999). O signo representa alguma coisa para alguém, criando em sua mente um signo equivalente. Nessa operação, gera-se um interpretante e aquilo que o signo representa é denominado seu objeto. Portanto, a representação ou o processo representativo caracteriza-se pela inter-relação entre signo-objeto-interpretante. Assim, conforme Santaella e Nöth (1999), os pensamentos se processam por meio de signos continuamente, fazendo com que as dimensões da cognição, da comunicação e da representação relacionem-se numa cadeia infinita de semiose.

Além da pesquisa bibliográfica,para a fundamentação teórico-conceitual, foi realizado um estudo de campo virtual, fundamentado na netnografia"l', com base em Amaral et al (2008), para compreender processos criativos-comunicacionais do artista por meio de seu acervo na web.

A netnografia, como transposição virtual das formas de pesquisa face a face e similares, apresenta vantagens explícitas tais como consumir menos tempo, ser menos dispendiosa e menos subjetiva, além de menos invasiva já que pode se comportar como uma janela ao olhar do pesquisador sobre comportamentos naturais de uma comunidade durante seu funcionamento, fora de um espaço fabricado para pesquisa, sem que este interfira diretamente no processo como participante 
fisicamente presente. Por outro lado, ela perde em termos de gestual e de contato presencial off-line que podem revelar nuances obnubiladas pelo texto escrito, emoticons, etc (AMARAL et al, 2008, p. 36).

Como aporte metodológico para leitura e análise das mensagens visuais, principalmente acerca da imagética audiovisual criada por Otoni Mesquita, nos embasamos na ideia de Coutinho (2006), que propõe traduzir códigos de linguagens artísticas mediante uma interpretação que não seja meramente perceptiva e descritivade aspectos técnicos, comunicacionais e artísticos, mas transcodifique o que é apreendido pelos sentidos, ao relacionar as circunstâncias onde seus componentes se inserem e se estabelecem imageticamente, já que não significam por si, enquanto imagens que são, mas dentro de contextos de representação. A complexa simultaneidade de elementos que as peças audiovisuais apresentam, objetiva e subliminarmente, assumindo seu lugar entre expressão e comunicação, pode gerar interpretações de maneiras diferenciadas.

Por esse motivo a análise da linguagem visual nos meios de comunicação audiovisuais (cinema, TV e vídeo) deve levar em conta uma espécie de "infra-saber", isto é, o conhecimento e compreensão das características discursivas da grande narrativa em que aquele registro visual se insere. Desta forma, ao atribuir sentido a cada imagem, e interpretá-la à luz das questões de pesquisa que orientam o projeto, é preciso considerar sua adequação ao estilo de linguagem do programa, filme ou categoria videográfica por meio do qual aquela mensagem visual é experimentada, ou consumida (COUTINHO, 2006, p. 343).

Portanto, para estabelecermos relações e interpretações sobre a produção audiovisual de Otoni Mesquita, foi necessário caracterizar aspectos da "grande narrativa do artista", ou seja, o conjunto de sua obra. Nos aproximamos desse amplo panorama, a partir de noções contextuais de sua vida e arte ou"vidarte", salientando que o trabalho do artista representa a realidade local, e repercute inquietações universais. Um corpo que é catalizador de ideias e ignição comunicacional.

Para Greiner (2005) o corpo não é apenas um recipiente e transmissor de informações, mas um organismo transformador em constante evolução pela contaminação entre o fluxo informacional que percorre seu contexto sensitivo interno e externo. As experiências decorrentes dessas relações geram comunicação, percepção e relação. A autora propõe pensar o corpo como um sistema complexo e interativo e não apenas como um instrumento, com um lado biológico e outro cultural, ou material e mental.

Em relação à arte, Greiner (2005) diz que o corpo muda cada vez que percebe o mundo, despertando metáforas mutantes que geram novas ações, caracterizando um "corpo artista". Isso porque o corpo é provido de uma dramaturgia que dá sentido e coerência ao fluxo incessante de informações entre o corpo e o ambiente.

O modo como ela se organiza em tempo e espaço é também o modo como as imagens do corpo se constroem no trânsito entre o dentro (imagens que não se vê, imagens-pensamentos) e o fora (imagens implementadas em ações) do corpo organizando-se como processos latentes de comunicação (GREINER, 2005, p. 73).

Nesse sentido, procuramos compreender Otoni Mesquitaanalisando seus arquivos de criação contemplando a diversidade de manifestações artísticas, 
as ramagens otonianas. Pois, além de indicarem aspectos de seu processo artístico e experimentações imagéticas, trazem um forte discurso político, de caráter étnico, social e ambiental. Procuramos mapear como se configuram essas ramificações, ao discutirmos seus fluxos, nas inter-relações e interdependências entre linguagens artísticas e seus entrelaçamentos com o ambiente que as envolve e outros sistemas.

Tal procedimento foi necessário para criar um contexto-conceitual a fim de prosseguirmos na segunda fase da investigação, voltada à análise de estéticas e processos relativos à produção de vídeos do artista, os experimentos audiovisuais. Assim, foi possível compreendermos suas peças audiovisuais dentro de um cenário complexo e não simplesmente como produções caseiras, realizadas em momentos recreativos ou em situações de protestos.

Portanto, na ebulição de uma mistura heterogênea, propomos uma interpretação relacional para partituras poético-visuais, inscritas na rota-transmutar da arte. Podemos dizer que a poética visual de Otoni Mesquita se estabelece como um recurso ecológico para dar sentido a reflexões de agora e outrora, percorrendo e fechando ciclos que se abrem para outros, mas, sem pontos de corte, pois ocorrem em fusão, atados por nós conectivos num tecer contínuo.

\section{Ramagens otonianas: desentranhando descobertas no estranhamento contemplativo}

Ramagens otonianas é a expressão poética que criamos para simbolizar a busca de uma compreensão ecossistêmica no tocante à "vidarte" de Otoni Mesquita. Podemos vislumbrar algumas imagens para ilustrar essa ideia, a exemplo do crescimento de uma planta, desde a semente, suas raízes, galhos, folhas, frutos e brotações; ou de uma rede neural provocando sinapses em cadeia; ou da contínua construção de uma teia relacional, em crescimento, com nós e interconexões que geram novas relações e significados. Um ecossistema comunicacional.

São ramificações que fluem a partir de um corpo-artista. Inquieto, original e criativo, que exerce sua expressividade com base em memórias, questionamentos, sonhos, técnicas, experimentações, relações interpessoais, perturbações, influências visuais, que se mesclam na transfiguração de uma estética ético-político-imagética, articulada num sistema sociocultural e ambiental, ecoando inquietações tanto pessoais quanto universais.

As interconexões são complexas e adquirem dinâmicas combinações pela ampla gama de atividades desenvolvidas pelo artista visualque também é historiador, jornalista, contista, ilustrador, educador social, professor universitário, performer e, sobretudo, um cidadão crítico que persegue ideais de sustentabilidade. Sem necessariamente levantar uma bandeira moralista, mas como uma espécie de força motrizpara processos artístico-comunicacionais.

Essas ramagens, que se hibridizam e se entrelaçam, são traduzidas e representadas em variadas manifestações, tecidas por diferentes linguagens artísticas. Embora Otoni Mesquita seja mais conhecido por suas pinturas, gravuras, esculturas e instalações, também revela-se em outras vertentes expressivas como a poesia, a performance, a atuação teatral e a produção de vídeos. Há mais de três décadas propõe experimentações audiovisuais, as quais se tornaram mais frequentes nos últimos anos, devido às facilidades dos recursos tecnológicos 
que permitem gravar, editar e exibir filmes com equipamentos caseiros.

Por essas peculiaridades, acreditamos que Otoni Mesquita seja um dos artistas mais instigantes no cenário cultural amazonense contemporâneo, destacando-se tanto por sua postura crítica em relação à sociedade, quanto pela criativa plasticidade do universo alegórico que representa em suas criações, voltadas principalmente à natureza e aos mitos amazônicos.

Esse breve relato inicial sobre Otoni Mesquita e a explanação que faremos a seguir tem base na netnografia realizada no perfil do artista no Facebook ${ }^{\mathrm{v}}$, que além de apresentar um vasto material de arquivo sobre suas criações, traz entrevistas concedidas a jornais e emissoras de TV, o que possibilitou extrair ricos depoimentos e impressões para análise e interpretação do seu processo de criação. A internet, segundo Salles (2010), pela mobilidade do ambiente on-line, expande as possibilidades de discutir a curadoria de processos criativos ou redes de criação. Pois, pelas dinâmicas interações proporcionadas na web, é possível estimular a criação de novos conceitos.

Essa proposta pode ser ampliada em duas direções: o número dos arquivos digitais de artistas (ou grupos de artistas) e os links teóricos responsáveis pelas interconexões. A ampliação viabilizaria o desenvolvimento de um ambiente digital colaborativo para discussão das redes de criação. Esses bancos de dados também poderiam gerar curadorias de processo de exposições virtuais, com a possibilidade de estarem sempre em expansão (SALLES, 2010, p. 218).

Por isso, antes de pincelarmos considerações sobre aspectos estéticos e de conteúdo em vídeosde Otoni Mes- quita é preciso que tenhamos uma breve noção contextual do conjunto de sua obra artística e suas motivações criativas. É importante reforçarmos que a análise do trabalho deste artista multifacetado é uma tarefa complexa devido a sua importância cultural no cenário da arte amazonense. Mas neste estudo não temos a intenção de abarcar tamanha dimensão, e por isso, vamos apenas pontuar algumas características. Essa aproximação é uma tentativa de compreender como a Amazônia se apresenta visualmente (e audiovisualmente) nos questionamentos sociais, políticos, culturais, ambientais e econômicos do artista.

Otoni Mesquita nasceu no município de Autazes (AM), em 1953. Mudou-se para Manaus com pouco mais de um ano de idade e teve uma infância marcada pelo exercício livre e criativo de desenhar e pintar. Por isso, acredita que a arte esteja intrínseca desde sempre em sua vida, fazendo parte de um processo tão natural quanto respirar, beber, caminhar e falar. Para Otoni "a arte é uma expressão que independe de vontade, é incandescente", como definiu o próprio artista em entrevista à jornalista e atriz Norma Araújo, no programa Via de Regra, dirigido pelo cineasta Roberto Kahane, em 1994, no período da exposição "Fragmentos, Bichos e Personas", no Centro Cultural Chaminé, em Manaus, e postada no dia 23 de dezembro de 2014, em sua página no Facebook.

Começou a atuar profissionalmente como artista plástico,em 1975, após participar de um curso livre promovido pela Pinacoteca do Estado do Amazonas, numa época em que ainda não havia um curso universitário de Artes em Manaus. Por isso, primeiramente, graduou-se em Comunicação Social (Jornalismo) pela Universidade Federal do Amazonas (1979), por acreditar que o curso era o que mais se aproximava das artes. De- 
pois de formado seguiu para o Rio de Janeiro, onde se graduou em Belas Artes (Gravura), pela Universidade Federal do Rio de Janeiro (1983). Prosseguiu seus estudos acadêmicos e obteve o título de mestre em Artes Visuais (1991) pela Universidade Federal do Rio de Janeiro e de doutor em História Social (2005) pela Universidade Federal Fluminense. Em 1994 passou a fazer parte do quadro de professores do Departamento de Artes da Universidade Federal do Amazonas e posteriormente tambémintegrou-se ao grupo de pesquisadores do Núcleo de Antropologia Visual da UFAM, voltado a pesquisas sobre cinema na Amazônia.

Seu currículo conta com a participação em mais de cem exposições coletivas e individuais, no Brasil, países da América do Sul e Estados Unidos, inclusive com a obtenção de prêmios em Salões de Arte. Além de ter publicado dois livros sobre história e arquitetura de Manaus, também atuou na gestão pública, no cargo de Coordenador do Patrimônio Histórico da Secretaria de Cultura do Estado do Amazonas.

Otoni Mesquita é movido pela vontade de externar sentimentos e se considera um "romântico", não no sentido sentimentalista, mas "pela eterna busca de ideais", como salienta em várias entrevistas disponíveis em seu arquivo. Não gosta de ser enquadrado em nenhuma corrente estética, mas assume uma grande influência do surrealismo, com tendências antropológicas e arqueológicas de cunho amazônico, por ser fascinado pelo ambiente que o cerca, desenvolvendo obras em variados suportes, gêneros e materiais.

O artista diz que traz em sua arte o somatório de experiências da infância, da imaginação, de inquietações, do repertório de leituras, de aprimoramento técnico, das viagens por diversos países, dos museus que conheceu, do comportamento e das expressões de pessoas, do que observa nos detalhes da arquitetura urbana e das paisagens naturais da Amazônia.

Sendo assim, quando contemplamos seus trabalhos, percebemos que em muitas de suas telas há estruturas que lembram catedrais ou templos de cidades perdidas, painéis com cenas de natureza, gravuras com grafismos que remetem à pinturas indígenas, desenhos de seres que são meio bicho e meio gente, esculturas que sugerem artefatos de civilizações antigas e a montagem de instalações onde todos esses elementos se conjugam. Quanto ao significado desse universo representativo, nem mesmo o artista sabe explicar, pois alega ser movido por forças inconscientes e prefere que cada espectador tenha a própria interpretação sobre suas obras. No entanto, acredita que em seu ímpeto expressivo também haja uma atitude consciente que é a busca pela harmonia entre o homem e a natureza.

Por isso, desde o início de sua carreira artística tem preferência por trabalhar com materiais recicláveis, como papel e papelão, além de objetos que encontra no quintal de casa e em suas andanças pelas ruas, recolhendo, reaproveitando e transformando o que o ambiente oferece, como ossos e espinhas de peixes, terra, troncos de madeira, galhos, folhas, raízes, fibras e penas. Para o artista esses materiais carregam histórias, têm impressa uma força que não há nos materiais comprados em lojas e proporcionam uma experimentação plástica mais desafiadora.

Para Salles (2010) a criação na arte tem uma relação direta do artista com seu ambiente e seu tempo, mas também se organiza por memórias, num percurso labiríntico que segue e deixa rastros. Muitas vezes, numa lógica de incertezas e também intervenções do acaso, o artista cria contextos para a leitura das obras. 
Esse processo complexo pode ser expresso numa amálgama de linguagens, uma trama de ideias, reminiscências, matérias-primas, objetos, formas, suportes, sentidos, espaços, impressões, sensações táteis, afetividades, sonoridades, aromas, que fazem do ato de criação um processo comunicativo e conectivo, que pode ser observado sob o ponto de vista de seus aspectos sociais, culturais e também subjetivos (SALLES, 2010).

A obra em construção carrega as marcas singulares do projeto poético que a direciona, que faz parte de complexas redes culturais, na medida em que se insere na frisa do tempo da arte, da ciência e da sociedade em geral. $O$ aspecto comunicativo do processo de criação envolve também uma grande diversidade de diálogos de natureza inter e intrapessoais: do artista com ele mesmo, com a obra em processo, com futuros receptores e com a crítica (SALLES, 2010, p. 89).

Em 2015 Otoni Mesquita completou quatro décadas de uma diversificada trajetória artística, portanto, seria inviável expor seu legado em um artigo. Como estratégia, buscamos identificar, no arcabouço de sua carreira, alguns traços ou facetas recorrentes. Encontramos esses indícios sintetizados em $\mathrm{Ci}$ clos do Eldorado, que não compreende uma fase específica da obra de Otoni Mesquita, mas é um tema recorrente de seu percurso criativo, sobre o qual interpreta e representa a Amazônia.

A escolha deste recorte metodológico é baseada na ideia de estética da continuidade, que, segundo Salles (2010), trata-se de uma busca pessoal ou um ideal perseguido pelo artista, para o qual não é possível precisar o ponto de origem, mas pode ser reflexo de indagações complexas que ao longo do tempo vão ganhando diferentes narrativas, com desdobramentos que podem ser inesgotáveis, pois o conjunto da obra de um artista também pode ser interpretado como o encadeamento de processos de transformação.

Desse modo, podemos dizer que a concepção e execução de uma obra de arte se dão no estabelecimento de relações e interdependências, numa permanente rede em construção, como um ecossistema comunicacional. Os processosque envolvem a criação, conforme Sales (2010),por mais que possam ter explicações racionais,são extremamente subjetivos e individuais, sendo assim, imagens, sons, temáticas, sensações, lembranças e quaisquer outras possibilidades sensoriais e expressivas, codificadas em obras artísticas, podem ser ressignificadas ou modificadas em diferentes momentos e contextos vivenciados pelo artista, sem que se percam da sua gênese conceitual.

As tendências do percurso podem ser observadas como atratores, que funcionam como uma espécie de campo gravitacional, indicando a possibilidade de determinados eventos ocorrerem. Nesse espaço de tendências vagas está o projeto poético do artista, princípios direcionadores, de natureza ética e estética, presentes nas práticas criadoras, relacionados à produção de uma obra específica e que atam a obra daquele criador como um todo (SALLES, 2010, p. 46).

\section{A sustentabilidade artística na reverberação de (((ecos))) ecopoiéticos}

Eco, em acústica, é reflexão sonora. A reverberação de um som, que se propaga... Eco, na ecologia, do grego oikos, é casa, e ecossistema é a casa em que se vive. Poiesis, também do grego, é criação e inspirou os bio-filósofos Francisco Varela e Humberto Maturana na 
ideia de autopoiese (autocriação). Sendo assim, para a arte de Otoni Mesquita, em livre abstração metafórica, dizemos que $((($ ecos $)))$ ecopoiéticos são as ideias que ressoam de um artista que cria e recria seu repertório imagético nas relações entre o humano, o social, o ambiental e acoplamentos tecnológicos, a partir das trocas de significados em que todos esses sistemas estão implicados. Dessa maneira, estabelece um conjunto relacional de linguagens e expressões artísticas que também são fenômenos ou objetos comunicacionais, passíveis de serem estudados e compreendidos em suas articulações e produção de sentidos.

Otoni, cidadão, amazonense, artista, historiador, educador, comunicador... Em todas essas atividades o seu discurso é ecológico. Vemos isso, entre outras atitudes,quando aponta o problema do lixo nas ruas por onde passa; contesta a derrubada de árvores para construção de um estacionamento;cria instalações chamando a atenção para a extinção de espécies;puxa os fios da história para evidenciar causas de problemas atuais; estimula a liberdade criativa em seus alunos na universidade; conversa com os visitantes de suas exposições; se insere nas comunidades onde ministra oficinas; critica o sistema econômico e político. Todas essas situações ficam evidentes em suas postagens diárias na internet, como um crítico feroz do comportamento "insustentável" da sociedade e também em suas entrevistas nos meios de comunicação tradicionais da mídia.

Mas o que é sustentável? Para Capra (2002) a ideia de sustentabilidade tem sido deturpada em torno de interesses políticos e econômicos, pelas redes do capitalismo global. Nesse sentido, o avanço científico e as inovações tecnológicas, têm ocasionado uma turbulência desarmônica e fora de controle, principalmente, por seus impactos sociais e ambientais. Se- gundo o autor as dinâmicas e interesses econômicos têm aumentado a pobreza, acentuado as desigualdades sociais e devastado a natureza. Portanto, um modelo insustentável, o qual, segundo o autor, necessitaria ser reestruturado desde as bases, começando pela forma de pensar o futuro do mundo.

Conforme Capra (2002) é importante não perder o senso de que todas as ações precisam atender as necessidades do presente sem comprometer as necessidades futuras, pois a sustentabilidade é a capacidade intrínseca de sustentar a vida de forma equilibrada, e o ser humano não pode prejudicar essa harmonia.

Esse é o sentido essencial da sustentabilidade ecológica. O que é sustentado numa comunidade sustentável não é o crescimento econômico nem o desenvolvimento, mas toda a teia da vida da qual depende, a longo prazo, a nossa própria sobrevivência. A comunidade sustentável é feita de tal forma que seus modos de vida, seus negócios, sua economia, suas estruturas físicas e suas tecnologias não se oponham à capacidade intrínseca da natureza de sustentar a vida (CAPRA, 2002, p. 224).

O autor complementa, enfatizando que a vida humana engloba necessidades biológicas, cognitivas e sociais que devem ser respeitadas.

A dimensão biológica inclui o direito de um ambiente sadio e alimentos seguros e saudáveis; o respeito à integridade da vida acarreta necessariamente a rejeição de patentes do registro de formas de vida. Os direitos humanos na dimensão cognitiva são, entre outros, o direito de acesso à educação e ao conhecimento e a liberdade de expressão e opinião. Na dimensão social, por fim, o primeiro direito humano 
- nas palavras da Declaração de Direitos Humanos da ONU - é "o direito à vida, à liberdade e à segurança da pessoa". Há muitos direitos humanos na dimensão social - da justiça social ao direito de reunir-se pacificamente, passando pelos direitos à integridade cultural e à autodeterminação (CAPRA, 2002, p. 224).

Essa confluência nos propõe que é preciso integrar o respeito aos direitos humanos e a sustentabilidade ecológica. A sociedade humana não é melhor, mas interage com os outros sistemas, e essa interação sustentável deve permitir que cada sistema se desenvolva de acordo com a sua natureza.

A sustentabilidade não pressupõe imutabilidade, mas um processo de coevolução, conforme Capra (2002). Os sistemas vivos são redes autogeradoras, que embora estejam em diferentes sistemas, são abertas a fluxos de energia e matéria. Assim, nas relações de interdependências, entreos elementos de um mesmo sistema ou entre diferentes sistemas interagentes, há comunicaçãoe compartilhamento em ciclos.

Para a sobrevivência, os organismos alimentam-se de fluxos contínuos de matéria e energia tiradas do ambiente em que vivem, produzem resíduos, que alimentam outra, continuamente circular, alianças, a vida se desenvolve pela cooperação e a organização em redes de diversidade quanto mais a diversidade maior a resistência, o equilíbrio dinâmico, as flutuações orbitais, que mesmo no caos mantém o equilíbrio (CAPRA, 2002).

A arte de Otoni Mesquita também propõe isto, como se pode perceber em Ciclos do Eldorado, em suas ramagens e seus experimentos. Desse modo, para a discussão que se segue, faremos um bre- ve mapeamento em torno das três exposições que marcam os Ciclos do Eldorado.

\section{Ciclos do Eldorado: a grande narrativa do artista}

As três mostras artísticas envolvendo o tema Ciclos do Eldorado provocaram inúmeros questionamentos sobre o processo de colonização e ocupação da Amazônia, reforçando ponderações sobre suas consequências. O encadeamento cíclico propõe reflexões críticas sobre a supressão de culturas ancestrais a partir da disseminação e manutenção da ideologia etnocêntrica europeia que perdura até os dias atuais.

Nas exposições transitam manifestações de diferentes linguagens desenvolvidas pelo artista, como pintura, gravura, instalação, indumentária, vídeo e performance. O material não foi observado in loco, haja vista que, quando nos propusemos a investigar a temática, a última exposição do artista já havia encerrado. Desse modo, optamos por acompanhar os registros feitos no museu virtual intitulado Memória da Exposição que o artista mantém em sua página no Facebook, com o portfólio fotográfico das mostras realizadas, informações técnicas, material de divulgação, críticas e resenhas, atividades extensivas à comunidade e experiências de bastidores, reunindo 442 postagens ${ }^{\vee}$.

Além de questões históricas e étnicas, as indagações do artista expuseram feridas sociais, ambientais e políticas, sobretudo, destacando o perigo da devastação da floresta em nome de um suposto desenvolvimento econômico. Como metáfora poética, plantas foram pintadas com tinta dourada, compondo instalações, para simbolizar que a verdadeira riqueza é a diversidade da Floresta Amazônica e não o ouro da mitológica 
cidade perdida, que aguçou a ganância dos exploradores europeus a partir do século XVI.Obviamente, a Amazônia continua excitando ambições mundiais, mas agora com outros interesses.

Em busca do Eldorado (2007) foia primeira exposição sobre o tema, mas apresentou reflexões e releituras visuais de criações do artista desde 1984, sendo realizada no Atelier Vila Venturosa, no Rio de Janeiro. Nessa fase o artista trabalhou uma série de gravuras feitas em metal com imagens que remetiam a referências da cultura pré-colombiana e uma pesquisa cromática no intuito de criar uma tonalidade de dourado que não fosse apenas material, mas traduzisse uma atmosfera sensorial do Eldorado. Algumas pinturas eram elaborações alegóricas sobre templos na floresta, mas que também sugeriam o aspecto de grandes catedrais de cidades europeias, fazendo uma analogia das riquezas minerais que eram levadas da Amazônia, evidenciando o processo violento que dizimou milhares de indígenas. Há também a presença das Personas, pinturas de figuras híbridas compostas por formas humanas, animais e míticas, com inspiração em grafismos da etnia Carajá e indumentárias da etnia Ticuna, e que seriam a interpretação do artista para o que ele chama "sincretismo amazônico".

Achados do Eldorado (2012/2014) foi a segunda exposição sobre o tema e percorreu três cidades brasileiras (Manaus, Belém e Rio). Permitiu a ampliação da experimentação visual com papel reciclado, relevos, arte digital, pintura, a coleta de vários tipos de terra, pedras e também materiais vegetais, como folhas, galhos e raízes. Estabelecendo uma espécie de jogo, no qual buscava enxergar nas andanças cotidianas ou em passeios na floresta e nas margens dos rios objetos e materiais que poderiam ser achados de uma civilização perdida, e a partir desses fragmentos criar instalações.Primeira- mente, o trabalho foi exposto na Galeria de Arte do Sesc Amazonas, em Manaus, em 2012, e no ano seguinte agregou outros elementos e foi exposta no $32^{\circ}$ Salão de Arte do Pará, no Museu Emílio Goeldi, em Belém (2013). Uma das peças dessa exposição, Oferendas da Floresta, foi apresentada na exposição Amazônia Ciclo de Modernidade, no Palácio da Justiça, em Manaus (2014), e no mesmo ano integrou a exposição Pororoca, no MAR, Museu de Arte do Rio, sendo adquirida para o acervo do museu.

Ciclos do Eldorado (2015/2016), a terceira exposição nesta temática, marcou os 40 anos de trajetória artística de Otoni Mesquita, fazendo um resgate dos trabalhos pregressos. Ficou em cartaz no Museu Amazônico, em Manaus, de dezembro de 2015 até fevereiro de 2016 , sendo ainda mais conceitual comparada às anteriores, reforçando o discurso crítico e reflexivo sobre o futuro do planeta, tratando de questões como o aquecimento global, o problema da água, a poluição a ocupação desordenada das cidades e o desmatamento das florestas, sobretudo, da Amazônia. $\mathrm{Na}$ abertura do evento, as Personas da primeira exposição transformaram-se em personagens "reais" numa performance interativa junto ao público. A exposição apresentou treze instalações, com o intuito de promover uma reflexão e possível discussão sobre aspectos ambientais e políticos que afetam o cotidiano da sociedade, especialmente a amazonense. Destacando-se: Buscas e Achados, composta por gravuras e papéis tratados com técnicas mistas. Oferendas Saqueadas, com ídolos dourados, cédulas de dinheiro, moedas e um altar, simbolizando o capitalismo e o apagamento das culturas ancestrais e seus símbolos. Seres do rio de água Doce, enfatizando o problema da água. Minha terra tem palmeiras, Tapetes da Floresta e a Construção do Deserto, elaboradas com 
diversos materiais orgânicos, tratam diretamente de questões da degradação ambiental e o superaquecimento global. Em Ciclo Gastronômico, elaborada com farinha, frutos, folhas, sementes e outros produtos naturais, o artista ironizou a apropriação da culinária regional em modismos da alta gastronomia. E em Promessas de Futuro expressa as incertezas sobre o que virá pela frente em nossa sociedade, entre possibilidades sustentáveis e atitudes marcadas pela ignorância ecológica.

Assim, a postura do artista torna-se uma atitude ecológica-ética-estética, um manifesto ecopoiético, no sentido de criação e autocriação, gerando transformações constantes na sua interação com o meio. Da reivindicação política ao sentimento de amor à natureza e a urgência por princípios sociais sustentáveis.

Desse modo, ao envolver diversas linguagens artísticas reconfiguradas no tempo e no espaço, o caráter cíclico de sua abordagem temática também pode ser interpretada como signos em transformação. Por exemplo: numa determinada exposição, o artista exibe uma gravura em meio a outros objetos e em outra exposição tal gravura passa a ser digitalizada e animada, reconfigurando-se em vídeo-arte; galhos, folhas, pedras e caracóis podem servir como elementos de uma instalação e em outro momento tornam-se composições numa fotografia; ou ainda, tecidos pintados com grafismos e vistos como faixas em uma ocasião, podem transformar-se em indumentária para uma performance e assim sucessivamente.

Podemos dizer que a semiose de Ciclos do Eldorado nos mapeia trajetórias ecossistêmicas, configurando e reconfigurando imaginários, por meio de memórias e metamorfoses, construindo novas cartografias sígnicas, numa transformação contínua no fluxo comunicativo, com suas inter-relações e interdependências, pois o processo de criação de Otoni Mesquita é caracterizado pela constante metamorfose e ressignificação de imagens.

As diferentes tendências e linguagens orbitam no mesmo campo gravitacional que dá uma espécie de unicidade ou identidade harmônica na elaboração de um ideal artístico, que por sua vez é influenciado por princípios éticos e estéticos, além de se manifestar num forte discurso ecológico, reforçando sua postura política crítica em relação ao processo histórico e suas reverberações na sociedade contemporânea. Podemos dizer que esse conjunto de atitudes configurem o que Salles (2010) compreende como o projeto poético do artista.

São princípios relativos à singularidade do artista: planos de valores, formas de representar o mundo, gostos e crenças que regem seu modo de ação. Esse projeto está inserido no espaço e no tempo da criação, que inevitavelmente afetam o artista. A busca pela concretização desse projeto é contínua, daí ser sempre incompleta; ao mesmo tempo, o próprio projeto se altera ao longo do tempo (SALLES, 2010, p. 46).

Portanto, visto por um ângulo mais aberto, a semiose do transcurso comunicativo que emerge da criatividade e postura ética de Otoni Mesquita, impulsiona inúmeras percepções e desdobramentos sobre processos socioculturais e ecológicos, "incomodando" e fazendo arte para a transformação social e política.

\section{Vide Otoni}

Como percebemos, o caráter comunicacional da "vidarte" de Otoni Mesquita, um corpo-artista com raízes subli- 
minares e ambiências relacionais,também se desdobra em manifestações do cotidiano, como nas redes sociais da internet, especialmente no Facebook, utilizado pelo artista como um jornal virtual ou um mosaico de ideias e reflexões. Assuntos que se conectam com os questionamentos expressados em Ciclos do Eldorado, evidenciando sua postura crítica, no intuito de chamar a atenção sobre manifestações artísticas, a transformação do espaço e a destruição da natureza.

No caso da internet, a mesma atmosfera "tempestuosa" criada em torno de suas manifestações artísticas se mantém no contexto cibernético. Ou seja, além da transmissão de informações, ideias e visualidades, há um fascinante refluxo estético no compartilhamento de sentidos, com dinâmicas e ressonâncias que variam conforme as sistemáticas envolvidas.

É nesse ambiente digital que Otoni Mesquita compartilha seus experimentos audiovisuais. Os interpretamos como espectros que, além da reverberação no espaço imagéticoe ecológico, são propulsores de reações multissensoriais, entretanto, quase sem notoriedade. Sugerimos essa concepçãopelo fato dos vídeos não despontarem entre suas expressões artísticas reconhecidas pela crítica e pelo público, pois são divulgados no âmbito de sua rede social na internet, como intervenções cotidianas.

Além de não estarem configuradas no rol "profissional" do artista parecem se caracterizar como um exercício lúdico, portanto, desabrocham despretensiosamente, como pequenas flores ou experimentos despojadamente livres, entre o emaranhado de suas ramagens. Os vídeos são curtos, têm em média dois minutos, sendo que alguns têm menos de 30 segundos e o mais longo, uma espécie de autodocumentário sobre a última exposição de Ciclos do Eldorado, decorre em sete minutos e quarenta e cinco segundos. Entretanto, todas as peças resplandecem a força do pensamento e a representação imagética de sua poética artística.

O corpus de análise, feita entre maio e agosto de 2016, reuniu 106 vídeos postados num período de três anos pelo artista. Em cada postagem, além do vídeo, disponível para visualização on-line, há uma descrição ou sinopse, na qual aparece o título, a técnica utilizada e algumas considerações sobre o contexto da obra. Outras informações e desdobramentos também são feitos durante os comentários e a interação do artista com os internautas, muitas vezes com opiniões bastante divergentes e conflituosas.

O primeiro vídeo, postado em 20 de junho de 2013, denominado Mana, Manaus ferveu. Foi bonita a festa, pai. Cheiro de alecrim..., refere-se a uma manifestação pública que reuniu cerca de 100 mil pessoas no centro da capital amazonense, integrando a série de protestos ocorridos em todo o Brasil no ano de 2013. O vídeo que tem um minuto e meio, foi gravado de cima de uma árvore por celular e mostra a passeata, com som ambiente, compreendendo a primeira parte do hino nacional brasileiro,cantado pelos manifestantes. É interessante a referência que o artista faz no título sobre as impressões dessa manifestação, inclusive, no cheiro que pairou pelo ar.

O último vídeo visualizado para a pesquisa, postado em 08 de agosto de 2006, é uma vinheta em animação artesanal, chamada Olimpíadas em Manaus (publicada três dias após o início da Olimpíada do Rio). Foi criada a partir de desenhos encomendados ao artista para o projeto de um aplicativo para celular que acabou sendo cancelado. Otoni aproveitou o material para fazer uma espécie de zombaria sobre modalidades esportivas que poderiam ser típicas competições 
manauaras,brincando com símbolos arquitetônicos de Manaus e arquétipos (ou seriam estereótipos?) amazônicos, como a figura do índio e das guerreiras amazonas. A trilha em estilo Noise Music, corrente musical que utiliza sonoridades dissonantes, foi acelerada, causando ainda mais estranheza.

Após essa breve apresentação, ressaltamos que neste trabalho o intuito não é fazer uma análise quantitativa ou qualitativa das peças audiovisuais, mas buscar conexões entre os vídeos e o projeto poético do artista, inserido no ambiente amazônico, considerando questões de linguagem, estética e representação. Diante disso, quando propomos uma análise dos fenômenos comunicativos por um viés complexo, percebemos que a comunicação vai muito além da relação funcionalista entre emissor-mensagem-receptor, afinal, estamos tratando de um contexto relacional compreendido por inter-relações e interdependências. Ou seja, além da transmissão da informação há um intrincado processo de significação e compartilhamento de sentidos, com dinâmicas e ressonâncias que variam conforme as sistemáticas envolvidas.

Os vídeos produzidos pelo artista são realizados com simplicidade tecnológica, utilizando basicamente os programas Photoshop, Moviemaker e MideaShow. As imagens são captadas por celular e editadas no computador de sua casa. Otoni geralmente é personagem dos próprios vídeos. Brinca com códigos da linguagem audiovisual, como os letreiros de abertura e os créditos finais com ficha a técnica, fazendo questão de enfatizar que ele é o "faz tudo". Os vídeos de Otoni, tem o artista como maestro absoluto. O própriocriador faz questão de reforçar essa opção, em respostas a comentários de internautas, quando explica que sua arte só pode ser feita por ele, não por uma questão de prepotência, mas de liberdade artística.
Usa trilhas sonoras de domínio público, para evitar problemas com direitos autorais, ou músicas autorizadas por amigos. Não é possível precisar se há uma elaboração prévia ou a ideia se efetiva no próprio processo de realização, pois não se notanem um apuro técnico em relação aos enquadramentos e à edição. Não são vídeos comerciais, não são exatamente videoarte ou videopoema, mas podem ser lidos, em princípio, como lúdicas experimentações sérias com uma aparência "caseira". No próximo item vamos discutir essas questões, por ora nos ateremos às percepções audiovisuais.

Uma das tendências no trabalho audiovisual de Otoni Mesquita é o registro de flagrantes do cotidiano. São cenas captadas pelo artista em diferentes situações, desdeuma caminhada por ruas de Manaus, passando pela reunião com amigos, a montagem de uma exposição, ou peripécias em viagens turísticas, por exemplo. O material posteriormente passa por uma edição, na qual o ritmo das imagens e do som ambiente geralmente são acelerados ou retardados para enfatizar a expressividade das situações. Eventualmente, opta pelo tratamento de cor e a mixagem do som ambiente com trilha sonora musical.

O fato é que Otoni conserva o frescor da curiosidade infantil, fazendo com que acontecimentos banais ganhem contornos pitorescos e cômicos, como um cachorro se coçando e rolando numa calçada, uma minhoca bailarina que dança entre os dedos do artista, a louca movimentação de formigas de bunda dourada, brincadeiras em uma aula de estamparia na faculdade de Artes, o embate entre um pavão e uma cotia em um parque no Rio de Janeiro, e até uma performance com a própria sombra projetada na parede de um prédio, com fusões e deslocamentos, conforme a passagem de carros em uma rua movimentada durante à noite. 
Labirinto da Caverna, postado em 5 de setembro de 2014, registra a performance de Otoni,ao pintar telas com grandes figuras humanas,cercado de um aparato de som e luz, num "processo show", em parceria com os artistas Fabiano Barros e Mazo Rodrigues, realizada em março de 2012, no Centro Cultural Povos da Amazônia. Já em Performance no ICBEU, com Nina e André, improvisa uma performance descontraída, durante a montagem de uma exposição coletiva, com dois amigos, quandose entrelaçam e ficam de perfil, fazendoexpressões corporais,em tríade sinuosa, subindo e descendo, imprimindo uma visualidade em movimento que lembra as pinturas de suas Personas.

Ainda na vertente de documentar o dia a dia, há peças de delicadeza lírica, como uma revoada de borboletas que formavam um tapete às margens de um rio, um bando de periquitos se aninhando em uma árvore no centro histórico de Manaus, o som da chuva captado à bordo de flutuante num igarapé. Já o cunho crítico sobre questões políticas, ideológicas e ambientais se expressa desde passeatas e manifestações sociais, até situações extremamente chocantes, como o desespero de um bicho-preguiça carregando o filhote após o desmatamento de uma área verde no campus da UFAM para a construção de um estacionamento.

Percebemos algumas reelaborações sobre o mesmo tema e o reaproveitamento de imagens. Por exemplo, o vídeo intitulado Dia das Bruxas em Manaus, postado em 31 de outubro de 2015, repleto de humor negro, faz uma crítica mordaz à falta de consciência ecológica, ao denunciar a situação de descaso em relação às toneladas lixo acumuladas na Praia da Manaus Moderna, no período de seca. Mostra também a questão do esgoto que é jogado sem tratamento no Rio Negro, de onde é retirada a água para o abastecimento da população manauara, evidenciando a negligência tanto da população quanto das autoridades governamentais e de órgãos de fiscalização. As imagens são reforçadas pela narração do próprio Otoni, feita no local, a partir das impressões do artista, com um tom que alia reportagem e fabulação, ao mostrar uma situação de risco ambiental e ironizar que as águas jorrando do esgoto seriam a "fonte das bruxas".

Posteriormente, o vídeo Olhar indiscreto sobre a cidade - por cima e pelas beiras , postado em 27 de maio de 2016, apresenta cenas panorâmicas de Manaus registradas do alto de um prédio. As vistas lembram cartões-postais, com o skyline do centro da cidade, detalhes da cúpula do Teatro Amazonas, a ponte sobre o Rio Negro, enquadrados em ângulos que transmitem a estabilidade de uma cidade bem urbanizada. Em seguida, corta para detalhes de esgoto sem tratamento, entulhos e lixo, um aglomerado de embarcações que servem de moradia para a população do entorno dos igarapés de Manaus. Ametáfora de abandono e caos atravessa,como uma espada,a paisagem idealizada de um cartão postal. Para essa segunda parte, utiliza-sedas imagens da praia que haviam ilustrado o vídeo citado anteriormente. Mas, neste caso não há qualquer narração ao vivo ou em off, toda a banda sonora é trabalhada com a música Perdi meu coração velho de autoria dos compositores e instrumentistas Zeca Torres Torrinho e Aldísio Filgueiras, poetas do cenário cultural amazônico, com versos que iniciam dizendo "olha pra essa paisagem de silêncio e paz, na moldura da parede armo a minha rede, devolve o meu verde verão...".

Outra tendência percebida nos vídeos de Otoni Mesquita é a digitalização de algumas de suas pinturas, gravuras e fotografias para posterior manipulação, animação e ressignificação. 
Em Genética da Obra, postado em 23 de agosto de 2014, o artista resgata trabalhos de 1983. São esboços feitos durante o curso de Belas Artes, nos quais representa construções e templos de cidades imaginárias e figuras humanas perfiladas que por meio digital vão se desmaterializando em fusões e distorções. Muitas dessas experiências gráficas iniciais tornaram-se características marcantes na obra de Otoni, como os Fragmentos e as Personas, que nesse vídeo regressam do passado, ou de suas origens imagéticas.

Reconstrução, postado em 24 de março de 2016, é a mutação de um desenho feito com canetinhas hidrocor e pincel atômico, em 1975, retrabalhado em Photoshop e animado em MovieMaker. No vídeo, um cubo em perspectiva, aos poucos se transforma numa figura humana estilizada, cheia de arestas geométricas, como se a pele fosse um jogo de xadrez, gerando embate com uma força interna querendo romper o traçado que a recobre e a enclausura. Quando consegue se libertar vai adquirindo formas orgânicas e figurativas até se transformar em curvas totalmente abstratas.

Em Mutante a cada instante, postado em 27 de março de 2016, o artista reprocessa digitalmente, estudos feitos em 2003, compostos por anotações e desenhos em caneta esferográfica, que se fundem a padrões e texturas elaborados para pinturas, relevos de reciclagem de papel, criando o que ele chama de "gravuras digitais", realizadas "num sábado meio nublado em Manaus”.

Em Caras e Bocas, postado em 01 de abril de 2015, resgata desenhos de uma caderneta de 1978, cujo propósito, na época, eram estudos para uma animação. A primeira parte do vídeo, que tem dois minutos, mostra uma mulher, em close, apenas delimitando seu rosto, fa- zendo caretas. Na segunda parte, a boca protagoniza a cena, com inúmeras possibilidades de movimentos entre os lábios, a língua e os dentes.

Um dos trabalhos que mais chama a atenção, tanto pelo contexto da concepção quanto pelo impacto audiovisual, é a animação Criação, postada em 30 dezembro de 2014. Na descrição do vídeo, o artista explica que em1979, na disciplina de Cinema, na fase de conclusão do curso de Comunicação, havia produzido mais de 400 telas para umaanimação que seria finalizada em película Super-8. O trabalho chegou a ser realizado, mas foi engavetado por não ter ficado satisfeito com o resultado. Trinta e cinco anos depois resolveu voltar àquela ideia e com equipamentos digitais retrabalhou a animação e a publicou em sua rede social, inclusive, atingindo um grande número de compartilhamentoselogiosos pela criatividade do vídeo. Nele, as aquarelas digitalizadas trazem uma gama de cores vibrantes, bichos e pessoas entram dançando e se transformam em letras, compondo a palavra "Desenho", em seguida palavras "Otoni Mesquita", fundem-se formando o contorno de cúpulas e minaretes de uma mesquita. A tela fica azul e entra uma bisnaga de tinta. Dos respingos surge um feto humano, que vai se desenvolvendo e sai andando, envelhece, vira luz, planta, árvore, planeta. Paralelamente a esta sequência, um peixe, que do mar salta para o ar, vira pássaro e depois astronauta. E assim, outros elementos que surgiram dos respingos de tinta vão interagindo entre si e se transformando, preenchendo a tela, compondo paisagens fantásticas e situações surreais, sempre em metamorfose, finalizando com uma bailarina que dança com o sol nas mãos, até virar pegadas de gente e tudo escurecer. A criação desse universo dura apenas um minuto. 
Opereta do solitário segue essa mesma poética mutante, com desenhos produzidos no final da década de 1970, misturando ideias da biogenética, transformação urbana das cidades, experiências místicas e extraterrestres, com trilha acelerada de Nino Rota, feita para o filme Casanova (Federico Fellini, 1976). Já o clip Lá vai Teteá, baseado em desenhos de 2002, animado em 2010 e postado 2014, mostra a metamorfose de três jovens caboclas sensuais que dançam, se exibem e aos poucos vão se deformando até "apodrecerem", com trilha acelerada, no rock pós-punk gótico, da banda escocesa Cocteau Twins.

Bonequitas de Goya, postado em 20 e janeiro de 2016, é um ensaio visual de dois minutos e quarenta e cinco segundos, homenagem ao pintor espanhol Francisco de Goya, que poderia ser até considerado um vídeo dança, a partir de uma sequência de fotografias de um guardanapo amassado, feito num voo entre Rio e Manaus. O vídeo, que tem um clima nostálgico pelos tons âmbar, remetendo à paleta cromática de Goya, é um balé digital e investiga a plasticidade da representação do corpo, explorando possibilidades de movimentos.

Assim, ao nos confrontarmos com esse mosaico, percebemos que os vídeos de Otoni Mesquita, são trabalhos repletos de simbologias e relações instigantes. Por serem produzidos num contexto mais despojado, deslocam a aura de um artista respeitado no cenário cultural amazonense para um campo instável e sem muitas definições que é a arte produzida para a web. Nesse sentido, o artista se joga vertiginosamente em queda livre, despencando num penhasco, sem medo de críticas e censuras.

Ao abordarmos essa temática, tomando como foco a configuração de um ecossistema comunicacional gerado a partir de aspectos da obra de Otoni Mesquita, acabamos por ampliar nossas percepções, do ponto de vista artístico, cultural, ecológico e político, ao constatarmos que por meio de memórias e metamorfoses o artista constrói um repertório sígnico por trajetórias ecossistêmicas, propondo inter-relações perceptivas de metáforas mutantes, ao sobrepor camadas entre o cotidiano social, os mitos, a natureza e o seu imaginário particular.

Por isso, acreditamos que ao enfatizarmos tais características também reverberemos reflexões sobre o mundo contemporâneo, sobretudo nos desdobramentos da produção de sentidos e de compromisso ético, por meio de um fluxo comunicacional, em prol de reflexões sobre sustentabilidade,justiça social e valorização artístico-cultural.

\section{Indefinições necessárias para definições desnecessárias}

As experiências no campo da videoarte, conforme Machado (1988), desde a década de 1960, propõe articular reflexões estéticas, o debate sobre o fazer artístico e suas relações com realidades urbanas, preocupações com a natureza e o desenvolvimento tecnológi$\mathrm{co}$, integrando diferentes suportes e linguagens por meio do vídeo, resultando em obras multimídias como videoinstalações, videoperformances, videoesculturas, videodança, videoclipe, videotexto e outras possibilidades.

Nesse sentido, além de pensar e repensar a questão da representação, transforma as relações da obra de arte com o espaço e o espectador, despertando outros olhares e perspectivas ampliadas sobre arte, comunicação, cultura e sociedade. Para não sair do 
foco, optamos por não aprofundar a discussão conceitual acerca da videoarte e suas diferentes esferas expressivas. Mas, achamos importante sinalizar que há inúmeras possibilidades de criação audiovisual que extrapolam os meios convencionais, como o cinema e a televisão.

Portanto, os vídeos de Otoni Mesquita na web também são possibilidades de expressão artística e comunicacional. Ao mesmo tempo em que assumem o livre exercício criativo da experimentação proporcionam inúmeras reflexões. Não são propriamente documentários nem ficções, no sentido clássico de gênero, mas são representações de realidades e devaneios tangíveis. Fortuitamente, evocam a gênese conceitual imbuída nas demais expressões artísticas que florescem do criador, que com seu espírito aberto às experiências do mundo vai reelaborando e construindo um universo particular, reflexo de seu imaginário, percepções, valores éticos e consciência cidadã.

Sem buscar enquadramentos conceituais, poderíamos dizer que em suas fábulas experimentais do cotidiano real; nas suas animações existenciais de sonhos; ou nos fragmentos de documentários da ilusão,a sua inventividade plástica e o seu discurso político ecoam, desafiando classificações habituais e ampliando a discussão sobre o caráter das representações, especialmente, em relação à Amazônia.

Da-Rin (2006) acredita que as abordagens teóricas sobre a produção audiovisual que fogem do convencional, sobretudo, obras de não-ficção, como o documentário contemporâneo que se apresenta de forma híbrida, se defrontam com um desafio quase intransponível para delimitar um campo conceitual. Por isso, é uma discussão complexa, que não deve ser esvaziada em tentativas simplistas de enquadrar por gêneros, estéticas e formatos.

Conforme Da-Rin (2006) o percurso da história do cinema traz,na diversidade de manifestações, uma fluidez estética que transmite ao entendimento contemporâneo a noção de que a produção audiovisual não cabe em fronteiras fáceis de se delimitar, pois implica em inscrever por imagens e sons, subjetividades, afetividades e valores. Para Da-Rin (2006) é importante contextualizar, pois não se pode conhecer uma realidade sem estar mediado por algum sistema significante, portanto, a superioridade de uma verdade absoluta deve ser desmitificada, fazendo até mesmo do gênero documentário um "constructo", assim como os filmes de ficção.

Travar um combate no campo simbólico não consiste meramente em reproduzir representações "verdadeiras" do mundo. Representações só assumem uma dimensão política quando seu sentido não se deixa aprisionar na univocidade e na totalidade. Uma pedagogia da imagem, no atual contexto audiovisual, é aquela que estimula o esvaziamento das agências de poder e promove o descentramento de suas representações prontas e acabadas (DA-RIN, 2006, p. 233).

Nesse sentido, acreditamos que os experimentos audiovisuais de Otoni Mesquita são manifestações que podem instigar questionamentos às estruturas de poder e suas verdades institucionais, denunciando o embuste das representações dominantes e a retórica que age sobre nós, buscando outras imagens, outros discursos e outras verdades.

Verdades fragmentárias, que estimulam uma subjetividade capaz de 
abordar mais criticamente opróprio processo social da produção de sentido. Um atributo cada vez mais importante, em meio ao dilúvio de representações que caracteriza o mundo contemporâneo, chamado por alguns de sociedade da imagem (DA-RIN, 2006, p. 224).

Metz (2007), a partir da reflexão de teóricos como André Bazin, Serguei Eisenstein, Bela Balázas, Rudolf Arnheim, também compreende o audiovisual (aborda o cinema, mas podemos trazer sua perspectiva para a nossa discussão) comoum campo complexo de ser analisado, porque é necessário compreender a fenomenologia da narração, ou seja, um sistema de transformações espaço-temporais e acontecimentos, numa sequência de elementos significantes visuais, verbais e sonoros.A compreensão de um universo diegético, proporcionado pela conjunção de uma gramática composta por diálogos, encenação, fotografia, trilha sonora etc., conforme Metz (2007), faz com que toda a impressão seja uma representação.

Portanto, além de ser constituído por uma essência intercambiável e complexa de códigos técnico-artísticos, próprios do universo audiovisual, ainda se articula entre ambientes configurados por elementos de ordem sociocultural, política, econômica e tecnológica, configurando um ecossistema que pressupõe a percepção e a relação para sua significação.

Desse modo, por ter tantas ambiguidades na especificidade de ser "uma linguagem que quer se tornar arte no seio de uma arte que, por sua vez, quer se tornar linguagem" (METZ, 2007,p.76), desencadeia inúmeras abordagens teóricas, metodológicas e procedimentos de investigação, tais como análise de discurso, análise de conteúdo, exploração etnográfica, pelo viés fenomenológico, sociológi- co, semiótico, pela psicologia da percepçãoentre outros.

Linguagem ou arte, o discurso imagético é um sistema aberto, difícil de codificar, com suas unidades de base não discretas (= as imagens), sua inteligibilidade por demais natural, sua ausência de distância entre significante e significado. Arte ou linguagem, o filme é composto por um sistema ainda mais aberto, com parcelas inteiras de significação que ele nos entrega diretamente (METZ, 2007, p. 76).

Nesse sentido, toda a construção que fazemos sobre a videografiaOtoniana, é significada pela teia de relações a partir da compreensão de sua "vidarte", apresentando-se como uma possibilidade de leitura, que não tem a intenção de esgotar-se em uma verdade, haja vista que estamos trabalhando com multi-expressões, em diferentes linguagens entrelaçadas, e sua decodificação é um conjunto de ações perceptivas, intelectivas, iconológicas, ideológicas etc., refletindo a combinação de relações que foi possívelestabelecer pelo pesquisador dentro da complexidade de um ecossistema, com muitas camadas simbólicas, e que se fundem a outros sistemas.

Os experimentos audiovisuais otonianos, nas contestações irônicas, inclusive ao fantasiar imaginários, tiramsuas máscaras e desmascaram a sociedade, em percepções anticonvencionais do mundo. Metamorfoseiam imagens-ideias-sensações, assumindo (trans)reconfigurações imprevistas. Assim, o artista canibaliza a sua própria arte, no universo iconofágico da cultura contemporânea, coma autenticidade do vivido e demostra que é impossível fugir das ambiguidades e apagar as memórias. 


\section{Bibliografia}

AMARAL, Adriana; NATAL, Geórgia; VIANA, Luciana. Netnografia como aporte metodológico da pesquisa em comunicação digital. Revista Sessões do Imaginário, Porto Alegre, v. 2, n. 20, p.34-40, dez. 2008.

CAPRA, Fritjof. As conexões ocultas: ciência para uma vida sustentável. São Paulo: Cultrix, 2002.

CAPRA, Fritjof. Teia da vida: uma nova compreensão científica dos sistemas vivos. São Paulo: Cultrix, 2006.

COUTINHO, lluska. Leitura e análise da imagem. In: DUARTE, Jorge; BARROS, Antônio (org.). Métodos e técnicas da pesquisa em comunicação. São Paulo: Atlas, 2008.

DA-RIN, Silvio. Espelho partido: tradição e transformação do documentário. Rio de Janeiro: Azougue Editorial, 2006.

GREINER, Christine. O corpo, pistas para estudos indisciplinares. São Paulo: Annablume, 2005.

MACHADO, Arlindo. A arte do vídeo. Editora Brasiliense: São Paulo, 1988.

METZ, Christian. A significação no cinema. São Paulo: Perspectiva, 2007.

MONTEIRO, Gilson Vieira; ABBUD, Maria Emília de Oliveira Pereira; PEREIRA, Mirna Feitosa (orgs.). Estudos e perspectivas dos ecossistemas na comunicação. Manaus: Edua/Ufam, 2012.

MORIN, Edgar. A cabeça bem-feita: repensar a reforma, reformar o pensamento. Rio de Janeiro: Bertrand, 2002.

SALLES, Cecília Almeida. Arquivos de Criação: arte e curadoria. São Paulo: FAPESP/ Ed. Horizonte, 2010.

SANTAELLA, Lucia. Culturas e artes do pós-humano: da cultura das mídias à cibercultura. São Paulo: Paulus, 2003.

SANTAELLA, Lucia; NÖTH, Winfried. Imagem, cognição, semiótica e mídia. São Paulo: lluminuras, 1999.
I Ítala Clay de Oliveira Freitas. Doutora em Comunicação e Semiótica pela PUC-SP. Diretora do Departamento de Cultura e Produção de Imagem e coordenadora da linha de pesquisa em Linguagens, representações e estéticas comunicacionais da Universidade Federal do Amazonas (UFAM). Professora do Programa de Pós-Graduação em Ciências da Comunicação da UFAM, Brasil. Contato: iclayfreitas@hotmail.com.

II Rafael de Figueiredo Lopes. Mestrando no Programa de Pós-Graduação em Ciências da Comunicação da Universidade Federal do Amazonas, na área de Ecossistemas Comunicacionais, sob orientação da Profa. Dra. Ítala Clay de Oliveira Freitas. Bolsista da Capes. Contato: rafaflopes@bol.com.br.

III A netnografia é um aporte metodológico de pesquisa em comunicação, no meio digital, que analisa o comportamento e as dinâmicas de sujeitos e grupos sociais na internet. É embasada na etnografia, método antropológico de pesquisa de campo para coleta, análise e interpretação de dados,configurado pelo caráter intersubjetivo entre pesquisador e objeto (AMARAL et al, 2008).

IV Portanto, temos consciência que observamos um recorte comunicacional por uma configuração digital, inclusive, com filtros e escolhas do próprio artista nas decisões de postagens, e não os objetos-sujeitos em si, concebidos e caracterizados em outros contextos, passíveis a outros desdobramentos, subjetividades e textualidades múltiplas.

V O álbum foi criado em 26 de janeiro de 2012, mas tem uma dinâmica contínua, pois acompanha o trajeto criativo do artista voltado à recorrente temática do Ciclos do Eldorado, portanto, o número referenciado de 442 postagens corresponde ao final do período de observação realizado para este estudo, em 12 de agosto de 2016 . 